University of Nebraska - Lincoln

DigitalCommons@University of Nebraska - Lincoln

PROGENY PRODUCTION AND DURATION OF DEVELOPMENT OF RUSTY GRAIN BEETLES, CRYPTOLESTES FERRUGINEUS (STEPHENS) (COLEOPTERA: CUCUJIDAE), ON CRACKED AND WHOLE CORN

James E. Throne

USDA-ARS, Manhattan, KS, james.throne@ars.usda.gov

Mark P. Culik

USDA-ARS

Follow this and additional works at: https://digitalcommons.unl.edu/usdaarsfacpub

Throne, James E. and Culik, Mark P., "PROGENY PRODUCTION AND DURATION OF DEVELOPMENT OF RUSTY GRAIN BEETLES, CRYPTOLESTES FERRUGINEUS (STEPHENS) (COLEOPTERA: CUCUJIDAE), ON CRACKED AND WHOLE CORN" (1989). Publications from USDA-ARS / UNL Faculty. 2047.

https://digitalcommons.unl.edu/usdaarsfacpub/2047

This Article is brought to you for free and open access by the U.S. Department of Agriculture: Agricultural Research Service, Lincoln, Nebraska at DigitalCommons@University of Nebraska - Lincoln. It has been accepted for inclusion in Publications from USDA-ARS / UNL Faculty by an authorized administrator of DigitalCommons@University of Nebraska - Lincoln. 


\title{
PROGENY PRODUCTION AND DURATION OF DEVELOPMENT OF RUSTY GRAIN BEETLES, CRYPTOLESTES FERRUGINEUS (STEPHENS) (COLEOPTERA: CUCUJIDAE), ON CRACKED AND WHOLE CORN ${ }^{1}$
}

\author{
James E. Throne and Mark P. Culik \\ Stored-Product Insects Research and Development Laboratory \\ Agricultural Research Service, U.S. Department of Agriculture \\ P.O. Box 22909, Savannah, GA 31403 \\ (Accepted for publication 5 August 1988)
}

\begin{abstract}
Progeny production and duration of development of rusty grain beetles, Cryptolestes ferrugineus (Stephens), maintained at 43 and $75 \% \mathrm{RH}$ were determined on whole and cracked corn. Number of progeny produced per female per day of oviposition ranged from 0 on whole corn maintained at $43 \% \mathrm{RH}$ to 2.2 on coarsely cracked corn maintained at $75 \% \mathrm{RH}$. Duration of development ranged from 6.1 weeks on coarsely cracked corn maintained at $75 \% \mathrm{RH}$ to 12.0 weeks on whole corn maintained at $43 \% \mathrm{RH}$. Progeny production was generally greatest and duration of development was generally shortest at $75 \%$ RH. Progeny production increased and duration of development decreased as particle size of cracked corn increased at $75 \%$ RH. Few progeny were produced on whole kernels.
\end{abstract}

Key Words: Insecta, development rate, progeny production, particle size, stored products, Zea mays, Cryptolestes ferrugineus, rusty grain beetle.

J. Entomol. Sci. 24(1): 150-155 (January 1989)

\section{INTRODUCTION}

The rusty grain beetle (RGB), Cryptolestes ferrugineus (Stephens), is a cosmopolitan pest of stored products, particularly stored grains (Throne 1987). RGB are frequently found in stored corn (Giles and Leon 1974; Horton 1982; Storey et al. 1983); however, only Sheppard (1936) has reported on the biology of RGB on corn. He reported that at $26.7^{\circ} \mathrm{C}$., the larval stage lasted 42 days on white or yellow corn meal. Larval mortality was 60 or $70 \%$, respectively. No larvae survived to the pupal stage on whole corn kernels. At $28.3^{\circ} \mathrm{C}$., the egg stage lasted 5 days on corn meal, the larval stage 32 to 37 days, and the pupal stage 5 days. Sixty pairs of adults produced 203 eggs over a 36 -day period in white corn meal.

Further biological studies are required to elucidate the population dynamics of RGB in corn. Studies on wheat indicate that the particle size of the grain - e.g., whole, coarsely cracked, or finely ground kernels - affects the number of progeny produced and the rate of development (Sheppard 1936; Mathlein 1971). A particle size of corn on which progeny production and duration of development are optimized would be preferred for mass rearing and many biological studies of RGB. We report here the number of progeny produced and duration of development of RGB on corn (Zea mays) of varying particle size.

\footnotetext{
${ }^{1}$ This article reports the results of research only. Mention of a proprietary product does not constitute an endorsement or a recommendation for its use by USDA.
} 


\section{MATERIALS AND METHODS}

\section{Test 1}

The objective of the first test was to determine the number of progeny produced on varying particle sizes of corn. The corn was 'Pioneer 3320 ', a variety commonly grown in the southeastern U.S. The corn was passed through a U.S. standard no. 6 sieve to remove dockage and was stored below $0^{\circ} \mathrm{C}$. for at least two weeks to kill insects that may have naturally infested the corn. A portion of the corn was cracked in a blender (Waring CB-6) and sieved to obtain a certain particle size. A separate portion of the corn was cracked to obtain each particle size. Particle sizes were whole (handpicked, undamaged kernels), coarsely cracked (retained on a no. 6, 3.35-mm sieve), medium cracked (passed through no. 6 but retained on no. $20,0.85-\mathrm{mm}$ sieve), and finely cracked (passed through no. 20 sieve).

Twenty replications of $20 \mathrm{ml}$ of each particle size of corn were placed in cylindrical plexiglass cages. Each cage consisted of two cylinders (32 mm i.d.; top$13 \mathrm{~mm}$ high; bottom- $25 \mathrm{~mm}$ high) taped together with each end covered with nylon screen (64 $\mu$ openings). Ten cages of each particle size were placed in each of two boxes containing humidity controlling salt solutions. The test was conducted at two relative humidities (43 and $75 \%$ ) because previous studies on wheat had shown that humidity affects the rate of RGB oviposition (Bishop 1959; Smith 1962, 1963, 1965), development (Rilett 1949; Bishop 1959), and survival (Rilett 1949; Bishop 1959). These relative humidities were chosen because the equilibrium moisture content of 'Pioneer 3320' corn stored at these humidities corresponds to the range of moisture contents at which corn is normally stored in the southeastern U.S., i.e., $11-15 \%$. Humidity was controlled with saturated salt solutions $\left(\mathrm{K}_{2} \mathrm{CO}_{3}-43 \%, \mathrm{NaCl}-\right.$ $75 \% \mathrm{RH}$; Greenspan 1977) under a perforated false floor in a covered plastic box (40 x $27.5 \times 16 \mathrm{~cm}$ high). A 300-g sample of whole corn was placed in each humidity box to check the moisture content weekly (with a Burroughs DMC-700 moisture computer).

The test was conducted at $30^{\circ} \mathrm{C}$, a temperature near the optimum for oviposition (Smith 1963, 1965), development (Rilett 1949; Smith 1965), and survival (Rilett 1949). The boxes were maintained in the dark throughout the study, except during examination.

One 20 to 27-day-old female was added in each of five replications of each treatment after the corn had equilibrated for six weeks (Block 1). The females were a first laboratory generation and were presumably mated. These females had been reared on a mixture of the various particle sizes of corn at $30^{\circ} \mathrm{C}$. One week later, one 20 to 27 -day-old female was added in the other five replications of each treatment (Block 2).

Females were removed from the cages after a two-week oviposition period, and their species and sex confirmed (Banks 1979). Beginning five weeks after the females were first placed on the corn, adult progeny were removed from the corn weekly, using an aspirator, until a second generation began to emerge. Samples were sifted once each week because more frequent disturbance may increase mortality (Loschiavo 1978). Samples were discarded if no adult progeny were found within 13 (Block 1) or 12 weeks (Block 2).

The test was arranged in a split-plot design with the two humidities as whole plots and the four particle sizes as subplots. There were two complete replications, 
or blocks, set up one week apart. The data were analyzed using the general linear models (GLM) and analysis of variance (ANOVA) procedures of SAS (SAS Institute 1985). All significant differences reported are $\mathrm{P}<0.05$.

\section{Test 2}

There were obvious differences in the first test in duration of immature development of RGB reared in the different particle sizes of corn. However, the oviposition period (two weeks) was too long to determine accurately the duration of immature development. Therefore we set up a second test, with a shorter oviposition period, to determine more accurately the duration of immature development on the different particle sizes of corn.

The design of the second test was similar to that of the first test, with a few changes. An additional treatment was whole, slit kernels. These were whole, undamaged kernels that were slit longitudinally through the germ with a razor blade $(<1 \mathrm{~mm}$ deep) to simulate damaged, whole kernels. Other changes in the classification of particle sizes were: 1) finely cracked corn passed through a no. 20 sieve but was retained on a no. $40(0.425 \mathrm{~mm})$ sieve, and 2) coarsely cracked corn passed through a $6.3-\mathrm{mm}$ sieve but was retained on a no. 6 sieve.

The cage was redesigned to simplify opening and reclosing. The top plexiglass cylinder ( $44.5 \mathrm{~mm}$ i.d. $\times 13 \mathrm{~mm}$ high) fit over the bottom ring $(38 \mathrm{~mm}$ i.d. $\times 25 \mathrm{~mm}$ high), and each end was again covered with nylon screen.

There were five replications of each treatment. Ten 3-5-week-old females were added to each cage after the corn had equilibrated at the two relative humidities. Females were removed after two days, and adult progeny were removed weekly, using an aspirator, beginning four weeks after females were placed on the corn. Samples were discarded if no adult progeny were found within 15 weeks. Other details of the design and analysis were as in the first test.

\section{RESULTS}

Moisture content of the 300-g samples of whole corn in the $\mathrm{K}_{2} \mathrm{CO}_{3}$ box was between 10.8 and $11.2 \%$ in both tests. Moisture content of the $300-\mathrm{g}$ sample in the $\mathrm{NaCl}$ box was between 14.6 and $15.0 \%$ in the first test and 13.6 and $14.7 \%$ in the second test.

\section{Number of Progeny Produced}

Number of progeny produced ranged from 0 progeny per female per day of oviposition on whole corn maintained at $43 \% \mathrm{RH}$ to 2.2 on coarsely cracked corn maintained at $75 \% \mathrm{RH}$. Significantly more progeny were produced on coarsely cracked and medium cracked corn held at $75 \% \mathrm{RH}$ in both tests (Table 1). Few progeny were produced on whole kernels. There were no significant differences in number of progeny produced in the two blocks set up one week apart in Test 1 $(\mathrm{F}=1.92 ; \mathrm{df} 1,1 ; \mathrm{P}>\mathrm{F}=0.40)$. There were significant differences in number of progeny produced on different particle sizes in both tests (Test $1: \mathrm{F}=53.4, \mathrm{df}=3$, $64, \mathrm{P}>\mathrm{F}=0.0001$; Test $2: \mathrm{F}=57.4, \mathrm{df}=4,40, \mathrm{P}>\mathrm{F}=0.0001)$. The humidity by particle size interaction was the only significant interaction in either test (Test 1 : $\mathrm{F}=16.73, \mathrm{df}=3,64, \mathrm{P}>\mathrm{F}=0.0001 ;$ Test $2: \mathrm{F}=22.29, \mathrm{df}=4,40, \mathrm{P}>\mathrm{F}=0.0001$ ).

\section{Duration of Development}

Duration of development ranged from 6.1 weeks on coarsely cracked corn maintained at $75 \% \mathrm{RH}$ to 12.0 weeks on whole corn maintained at $43 \% \mathrm{RH}$. 
Duration of development was shortest on coarsely cracked kernels maintained at $75 \% \mathrm{RH}$ in Test 1 and on coarsely cracked or whole slit kernels maintained at $75 \%$ RH in Test 2 (Table 2 ). There were no significant differences in duration of development in the two blocks set up one week apart in Test $1(\mathrm{~F}=0.01 ; \mathrm{df}=1$, 51; $\mathrm{P}>\mathrm{F}=0.92$ ). There were significant differences in duration of development on different particle sizes in both tests (Test 1: $\mathrm{F}=6.6$, $\mathrm{df}=3,51, \mathrm{P}>\mathrm{F}=0.0007$; Test $2: \mathrm{F}=17.7, \mathrm{df}=4,34 ; \mathrm{P}>\mathrm{F}=0.0001)$. The only significant interaction was the humidity by particle size interaction in the second test $(F=11.89$; $d f=4,34$; $\mathrm{P}>\mathrm{F}=0.0001$ ).

\section{DISCUSSION}

Duration of development of immature stages in the present study was about twice as long as that reported in previous studies on wheat conducted at $32.2^{\circ} \mathrm{C}$. (Rilett 1949; Bishop 1959), but was about the same as that reported in a previous study using corn and conducted at $28.3^{\circ} \mathrm{C}$. (Sheppard 1936). This indicates that wheat may be a more suitable host for RGB than corn.

More progeny were produced and duration of development was generally shorter in corn fractions maintained at $75 \% \mathrm{RH}$ than those held at $43 \% \mathrm{RH}$. These results are consistent with results of previous studies on wheat (Rilett 1949; Bishop 1959). The greater number of progeny produced at higher humidities may be due to a higher rate of oviposition (Bishop 1959; Smith 1962, 1963, 1965) or to increased survival of immature stages (Rilett 1949; Bishop 1959).

More progeny were produced and duration of development was generally shorter in larger particles at the higher humidity. No previous study has determined

Table 1. Number of $C$. ferrugineus progeny produced on corn of varying particle size at $30^{\circ} \mathrm{C}$ and two humidities.*

\begin{tabular}{|c|c|c|c|c|}
\hline \multirow[b]{2}{*}{ Particle size } & \multicolumn{2}{|c|}{ Test $1^{\dagger}$} & \multicolumn{2}{|c|}{ Test $2 \ddagger$} \\
\hline & $\overline{\mathrm{X}}$ & SEM & $\overline{\mathrm{X}}$ & SEM \\
\hline \multicolumn{5}{|c|}{$43 \% R H$} \\
\hline Fine & $6.7 \mathrm{~d}$ & 1.2 & $11.4 \mathrm{c}$ & 0.9 \\
\hline Medium & $16.9 \mathrm{c}$ & 1.6 & $11.2 \mathrm{~cd}$ & 2.3 \\
\hline Coarse & $6.0 \mathrm{~d}$ & 0.9 & $11.6 \mathrm{c}$ & 1.4 \\
\hline Whole, slit & ---- & ---- & 0.8 ef & 0.4 \\
\hline Whole & 0 & 0 & $0.2 \mathrm{f}$ & 0.2 \\
\hline \multicolumn{5}{|c|}{$75 \% R H$} \\
\hline Fine & $17.6 \mathrm{c}$ & 1.5 & $9.2 \mathrm{~cd}$ & 1.6 \\
\hline Medium & $23.2 \mathrm{~b}$ & 1.9 & $21.6 \mathrm{~b}$ & 2.5 \\
\hline Coarse & $30.0 \mathrm{a}$ & 3.5 & $43.0 \mathrm{a}$ & 4.5 \\
\hline Whole, slit & ---- & --- & $5.8 \mathrm{de}$ & 0.5 \\
\hline Whole & $1.2 \mathrm{e}$ & 0.4 & $3.2 \mathrm{ef}$ & 0.7 \\
\hline
\end{tabular}

Means in the same column followed by the same letter are not significantly different ( $\mathrm{P}=0.05$; LSD).

* Moisture content of whole corn maintained at $43 \%$ RH was between 10.8 and $11.2 \%$ in both tests. Moisture content of whole corm maintained at $75 \% \mathrm{RH}$ was between 14.6 and $15.0 \%$ in Test 1 and 13.6 and $14.7 \%$ in Test 2. See text for differences in particle sizes between the two tests.

$\dagger$ One female oviposited for two weeks. Number of replications is ten.

$\ddagger$ Ten females oviposited for two days. Number of replications is five. 
Table 2. Duration of development (weeks) of C. ferrugineus progeny reared on corn of varying particle size at $30^{\circ} \mathrm{C}$ and two humidities.*

\begin{tabular}{|c|c|c|c|c|c|c|}
\hline \multirow[b]{2}{*}{ Particle size } & \multicolumn{3}{|c|}{ Test $1^{\dagger}$} & \multicolumn{3}{|c|}{ Test $2 \ddagger$} \\
\hline & $\overline{\mathrm{x}}$ & SEM & $\mathrm{n}$ & $\overline{\mathrm{x}}$ & SEM & $\mathrm{n}$ \\
\hline \multicolumn{7}{|c|}{$43 \% R H$} \\
\hline Fine & 9.9 & 0.4 & 9 & $8.1 \mathrm{~d}$ & 0.3 & 5 \\
\hline Medium & 8.4 & 0.1 & 10 & $8.8 \mathrm{~cd}$ & 0.3 & 5 \\
\hline Coarse & 8.4 & 0.3 & 10 & $8.0 \mathrm{~d}$ & 0.2 & 5 \\
\hline Whole, slit & --- & --- & -- & $7.8 \mathrm{de}$ & 0.6 & 3 \\
\hline Whole & --- & --- & -- & $12.0 \mathrm{a}$ & --- & 1 \\
\hline \multicolumn{7}{|c|}{$75 \% R H$} \\
\hline Fine & 9.6 & 0.5 & 10 & $10.3 \mathrm{ab}$ & 0.5 & 5 \\
\hline Medium & 8.3 & 0.4 & 10 & $9.6 \mathrm{bc}$ & 0.4 & 5 \\
\hline Coarse & 6.8 & 0.1 & 10 & $6.1 \mathrm{f}$ & 0.1 & 5 \\
\hline Whole, slit & --- & --- & -- & $6.8 \mathrm{ef}$ & 0.2 & 5 \\
\hline Whole & 7.8 & 0.4 & 6 & $8.0 \mathrm{~d}$ & 0.7 & 5 \\
\hline
\end{tabular}

Means in the same column followed by the same letter are not significantly different $(\mathrm{P}=0.05$; LSD)

* Moisture content of whole corn maintained at $43 \%$ RH was between 10.8 and $11.2 \%$ in both tests. Moisture content of whole corn maintained at $75 \%$ RH was between 14.6 and $15.0 \%$ in Test 1 and 13.6 and $14.7 \%$ in Test 2 . See text for differences in particle sizes between the two tests.

$\dagger$ One female oviposited for two weeks. $\mathrm{n}$ is the number of replications. The value for each replication was the average duration of development for all progeny emerging within one cage.

¥Ten females oviposited for two days. $\mathrm{n}$ is the number of replications. The value for each replication was the average duration of development for all progeny emerging within one cage.

the effects of a range of particle sizes on RGB development. Larger grain particles may protect immature RGB. Normally eggs are laid in crevices in whole or broken kernels, and larvae and pupae develop within the kernel. If kernels are too small for larvae to burrow inside, then the immature stages are subject to mechanical damage and cannibalism. RGB larvae readily eat RGB eggs, larvae, and pupae (Sheppard 1936).

Few progeny were produced on whole kernels. Sheppard (1936) reported that whole wheat kernels were satisfactory for RGB larval growth, whereas no larvae reared on whole corn kernels survived to the pupal stage. Rilett (1949) reported that RGB larvae were unable to burrow into whole wheat kernels unless there was a break in the seed coat. However, half of the kernels that appeared undamaged actually had microscopic breaks in the seed coat and were suitable for RGB development. In the present study, slitting the seed coat did not greatly increase the number of progeny produced on whole corn. Mathlein (1971) reported that wheat kernels without microscopic breaks in the seed coat were not invulnerable to RGB attack. However, reproduction was much greater on cracked wheat.

The results of the present study show that the number of progeny produced and rate of development of RGB are optimized on coarsely cracked corn maintained at a high humidity. A number of further inquiries are suggested by these results. The corn fractions may not reach the same equilibrium moisture content, so differences in progeny production and development rate may be due to differences in moisture content. The rates of oviposition and survival may vary among the particle sizes. The infestation of whole kernels may vary with density of RGB. Under field conditions, RGB may feed on less suitable particle sizes of grain because of competition. 


\section{ACKNOWLEDGMENTS}

We thank K. P. Burnham for assisting with the statistical analysis, and F. H. Arthur, J. E. Baker, L. D. Cline, D. W. Hagstrum, and D. E. Legg for helpful comments on a draft of the manuscript.

\section{LITERATURE CITED}

Banks, H. J. 1979. Identification of stored product Cryptolestes spp. (Coleoptera: Cucujidae): a rapid technique for preparation of suitable mounts. J. Aust. Entomol. Soc. 18: 217-22.

Bishop, G. W. 1959. The comparative bionomics of American Cryptolestes (Coleoptera-Cucujidae) that infest stored grain. Ann. Entomol. Soc. Am. 52: 657-65.

Giles, P. H., and O. Leon. 1974. Infestation problems in farm-stored maize in Nicaragua. Pages 68-76 in Proceedings of the First International Working Con-ference on StoredProduct Entomology. Savannah, Georgia, USA. October 7-11, 1974.

Greenspan, L. 1977. Humidity fixed points of binary saturated aqueous solutions. J. Res. Natl. Bur. Stand., Sect. A 81: 89-6.

Horton, P. M. 1982. Stored product insects collected from on-farm storage in South Carolina. J. Ga. Entomol. Soc. 17: 485-91.

Loschiavo, S. R. 1978. Effect of disturbance of wheat on four species of stored-product insects. J. Econ. Entomol. 71: 888-93.

Mathlein, R. 1971. Rearing experiments with Oryzaephilus surinamensis L. and Cryptolestes errugineus Steph. on grain. Medd. Statens Växtskyddsanstalt 15: 187-03.

Rilett, R. O. 1949. The biology of Laemophloeus ferrugineus (Steph.). Can. J. Res., Sect. D 27: 112-48.

SAS Institute. 1985. SAS User's Guide: Statistics, Version 5 Edition. SAS Institute Inc., Cary, NC.

Sheppard, E. H. 1936. Note on Cryptolestes ferrugineus Steph., a cucujid occurring in the Trichogramma minutum parasite laboratory of Colorado State College. Colo., Agr. Exp. Stn., Tech. Bull. 17, 20 pp.

Smith, L. B. 1962. Observations on the oviposition rate of the rusty grain beetle, Cryptolestes ferrugineus (Steph.) (Coleoptera: Cucujidae). Ann. Entomol. Soc. Am. 55: 77-82.

Smith, L. B. 1963. The effect of temperature and humidity on the oviposition of the rusty grain beetle, Cryptolestes ferrugineus (Steph.). Proc. North Cent. Branch Entomol. Soc. Am. 18: 74-6.

Smith, L. B. 1965. The intrinsic rate of natural increase of Cryptolestes ferrugineus (Stephens) (Coleoptera, Cucujidae). J. Stored Prod. Res. 1: 35-49.

Storey, C. L., D. B. Sauer, and D. Walker. 1983. Insect populations in wheat, corn, and oats stored on the farm. J. Econ. Entomol. 76: 1323-30.

Throne, J. E. 1987. A bibliography of the rusty grain beetle, Cryptolestes ferrugineus (Stephens) (Coleoptera: Cucujidae). US Dep. Agric., Agric. Res. Serv., ARS-67, 19 pp. 